\title{
Disparate Effects of Roscovitine on Renal Tubular Epithelial Cell Apoptosis and Senescence: Implications for Autosomal Dominant Polycystic Kidney Disease
}

\author{
Jin-Young Park ${ }^{a, c}$ See-Hyoung Park ${ }^{a, d}$ Robert H. Weiss ${ }^{a-e}$ \\ a Division of Nephrology, Department of Internal Medicine, ${ }^{b}$ Cancer Center and ${ }^{\mathrm{C}}$ Immunology and

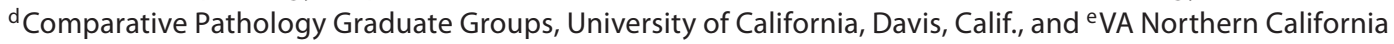 \\ Health Care System, Sacramento, Calif., USA
}

\section{Key Words}

Autosomal dominant polycystic kidney disease $\cdot$ p21 •

Apoptosis · Senescence discovery of senescence induced by a PKD effective drug suggests a new area of therapeutic investigation in this disease.

\begin{abstract}
Background/Aims: Control of apoptosis in autosomal dominant polycystic kidney disease (ADPKD) and in at least some cancers is likely regulated by the endogenous cyclin kinase inhibitor p21, levels of this protein being decreased in ADPKD and increased in many malignancies. The cyclin kinase inhibitor roscovitine has shown efficacy in treatment of murine PKD. We asked how a single agent can be efficacious in both PKD and cancer. Methods: Renal tubular epithelial cells were incubated at diverse roscovitine concentrations; apoptosis and senescence were measured. Subsequently, levels of pro- and antiapoptotic proteins were evaluated. $\boldsymbol{R} \boldsymbol{e}$ sults: Renal tubular epithelial cells exposed to 'low' concentrations of roscovitine showed minimal apoptosis in association with markedly increased levels of the antiapoptotic protein p21, and these cells became senescent. Conversely, cells exposed to 'high' levels of roscovitine became apoptotic. The mechanism of antiapoptosis and senescence with 'low'-dose roscovitine involves augmentation of the antiapoptotic proteins. Conclusions: Data in this study provide a mechanistic explanation of how roscovitine is effective in PKD, and suggest that further study of this agent should focus on assessment of dose response. Furthermore, our
\end{abstract}

\section{Background}

The pathobiology of polycystic kidney disease (PKD) at the molecular level involves aberrant cell cycle progression in a similar fashion to cancer, such that PKD has been labeled 'neoplasia in disguise' [1]. However, PKD is associated with increased levels of apoptosis [2], whereas the opposite is true of cancers which are in nearly all instances characterized by suppression of apoptosis [3]. In fact, the goal of cancer therapy is to increase apoptosis in malignant cells, whereas in PKD, such an increase in an already amplified process is likely detrimental [4].

While possessing pleiotropic effects, the cyclin-dependent kinase (CDK) inhibitor $21^{\text {waf1/cipl }}$ generally suppresses cell proliferation and decreases apoptosis in mesenchyme-derived cells [5]. Polycystin-1, whose gene is mutated in $85 \%$ of human autosomal dominant PKD (ADPKD), increases expression of p21 [6], and p21 is decreased in human and a rat model of PKD [7]; these findings are consistent with the observed augmentation of both cell proliferation and apoptosis in this disease.

\section{KARGER}

Fax +4161306 1234 E-Mail karger@karger.ch www.karger.com
(C) 2008 S. Karger AG, Basel

0250-8095/09/0296-0509\$26.00/0

Accessible online at:

www.karger.com/ajn
Dr. Robert H. Weiss

Division of Nephrology, Department of Internal Medicine

Genome and Biomedical Sciences Building, Room 6312

University of California, One Shields Ave., Davis, CA 95616 (USA)

Tel. +1 530752 4010, Fax +1 530752 3791, E-Mail rhweiss@ucdavis.edu 
While the chemotherapeutic agent and CDK inhibitor roscovitine was recently shown to exert salutary effects on a mouse model of PKD [8], the mechanism by which this drug exerts these effects is not known. In particular, it is unclear how this kinase inhibitor can have beneficial effects in cancer, in which the goal is to kill the offending malignant cells, and in PKD, where the objective is to prevent proliferation and decrease apoptosis. We now show that roscovitine has opposing outcomes on renal tubular epithelial (RTE) cell apoptosis depending on its concentration. In addition, we show that the mechanism of roscovitine's beneficial effect in PKD is likely through induction of cell senescence, rather than apoptosis. Our work will lead to careful assessment of dose response while using this drug in both clinical and research settings, and will open new avenues of therapeutic investigation for PKD focusing on the induction of RTE replicative senescence.

\section{Methods}

\section{Materials and Cell Culture}

Roscovitine was purchased from Sigma (St. Louis, Mo., USA). The Senescence Detection Kit was purchased from Biovision (Mountain View, Calif., USA). MDCK and HEK293 cells were obtained as kind gifts from Dr. John Payne and Dr. Elva Diaz, respectively, at the University of California, Davis. WT 9-7 cells (derived from a human ADPKD proximal tubule cyst) were obtained from ATCC; all cell lines were maintained in Dulbecco's media, $10 \%$ fetal bovine serum and $1 \%$ Pen/Strep. Mouse monoclonal antirecombinant full-length $\mathrm{p} 21^{\mathrm{Waf1} / \mathrm{Cip} 1}$ antibody was obtained from Upstate Biotechnology (Lake Placid, N.Y., USA), p53 antibody was obtained from Santa Cruz Biotechnology (Santa Cruz, Calif., USA), and mouse anti-PARP purified antibody and apoptosis detection kit were obtained from BD Biosciences (San Diego, Calif., USA). Phospho-p53 antibody $\left(\mathrm{pSer}^{15}\right)$, phospho-Akt antibody (pSer ${ }^{473}$ ) and phospho-Bad antibody sampler kit were obtained from Cell Signaling Technology (Danvers, Mass., USA). Goat anti-mouse and goat anti-rabbit horseradish peroxidaseconjugated IgG were obtained from Bio-Rad (Richmond, Calif., USA). Mouse anti- $\beta$-actin monoclonal antibody was from SigmaAldrich (St. Louis, Mo., USA). ECL Western blotting detection reagents were obtained from Amersham Biosciences (Little Chalfont, UK). For roscovitine treatment, cells were seeded for $24 \mathrm{~h}$ before treatment and roscovitine was added to the cells in serumcontaining media and incubated for $24 \mathrm{~h}$.

\section{Immunoblotting}

Western blotting was performed as previously described [7].

Assessment of SA- $\beta$-Galactosidase Activity as a Measure of Senescence [9]

The vendor's instructions were followed. Briefly, cells were seeded $24 \mathrm{~h}$ before roscovitine treatment and roscovitine was added to the cells with serum-containing media for an additional
$24 \mathrm{~h}$. Cells were incubated with staining mixture overnight and observed under a microscope under visible light. Blue-stained cells and the total number of cells were counted to calculate the percentage of cells expressing $\beta$-galactosidase. After data acquisition, raw images were opened with Powerpoint and images were processed with the built-in adjustment function of 'auto levels', 'auto contrast', and 'auto color'. Contrast was adjusted in panels showing blue staining for better visualization. No further image manipulation occurred.

Caspase Assay

The CaspACE assay kit (Promega, Madison, Wisc., USA) was utilized following the manufacturer's instructions. Briefly, cells were harvested, washed, and equal protein quantities were incubated with the DEVD-pNA caspase-3 substrate in caspase assay buffer. Color development was measured at $405 \mathrm{~nm}$.

\section{Results}

Roscovitine has been shown to be effective in cancer and, more recently, in murine PKD. This is enigmatic, since cancer therapeutics generally act through induction of apoptosis, while ADPKD is already a highly apoptotic disease in which this biochemical event likely contributes to its pathogenesis [reviewed in 10]. We have previously shown that $\mathrm{p} 21$ is increased in MDCK cells in a roscovitine dose-dependent manner from 1 to $10 \mu \mathrm{g} / \mathrm{ml}$ [7]. In order to determine the consequence of roscovitine incubation on RTE cells over a wider range of concentrations, we incubated MDCK cells growing in 10\% serum-containing media ('complete' media) with roscovitine at 'low' $(5-10 \mu \mathrm{g} / \mathrm{ml})$ and 'high' $(20-40 \mu \mathrm{g} / \mathrm{ml})$ concentrations and examined levels of both PARP cleavage, as a measure of apoptosis, and p21, a CDK inhibitor with antiapoptotic effects $[11,12]$. At high concentrations, roscovitine resulted in PARP cleavage, while at low concentrations, there was no apoptosis and p21 was elevated (fig. 1a). Surprisingly, there was an abrupt change in both p21 levels and apoptosis between the 5 - and $20-\mu \mathrm{g} / \mathrm{ml}$ concentrations of roscovitine, an event which was confirmed in an additional RTE 'normal' cell line, human HEK293 cells (fig. 1b), and an ADPKD human cell line (WT 9-7) (fig. 1c); the latter cells showed different sensitivity to roscovitine.

To confirm that apoptosis is indeed occurring at high, but not low, roscovitine concentrations, we repeated the MDCK cell experiment at smaller concentration increments and examined activation of caspase- 3 as another measure of apoptosis. Caspase-3 activity was significantly increased from control cells at 16 and $20 \mu \mathrm{g} / \mathrm{ml} \mathrm{rosco-}$ vitine (fig. 2), a finding which paralleled PARP cleavage (compare fig. 1a) and was inversely correlated with p21 

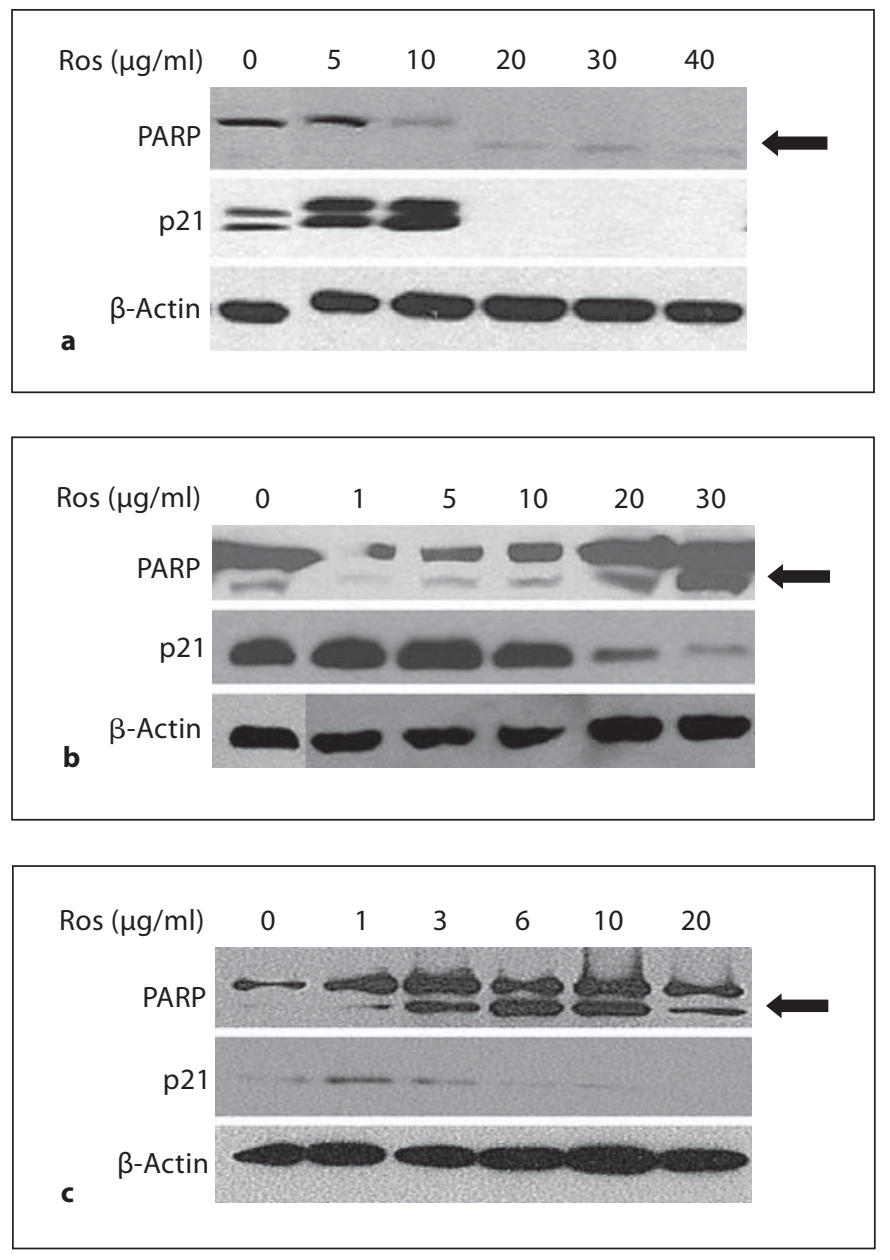

Fig. 1. Roscovitine (Ros) displays concentration-dependent effects on p21 and on apoptosis in RTE cells. MDCK (a), HEK293 (b) and WT 9-7 (c) cells were grown to confluence in 10\% serumcontaining media (complete media without roscovitine) and roscovitine was added at the indicated concentrations for $24 \mathrm{~h}$. Subsequently, the cells were lysed and immunoblotted with the antibodies indicated. Arrow indicates the cleavage product of PARP. $\beta$-Actin is a loading control.

levels (lower panel in fig. 2) confirming apoptosis with high-dose, but not low-dose, roscovitine.

The role of apoptosis in PKD has been intensively investigated, yet there exists conflicting data on this point. While in general it appears that inhibition of apoptosis in PKD has salutary effects [13-15], there is also data showing that the induction of apoptosis associated with mTOR inhibition by rapamycin results in a reduction of cyst growth in mouse models of PKD [16, 17]. Thus, while the function of apoptosis in the disease is controversial, the induction of replicative senescence, the state of irrevers-

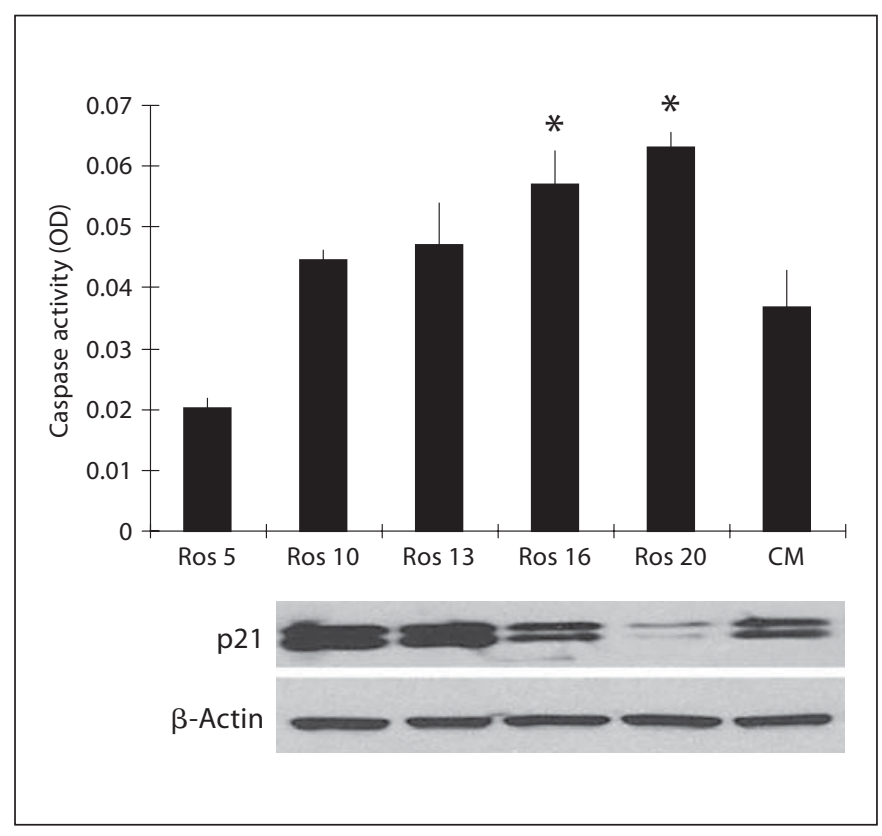

Fig. 2. Caspase-3 activity is increased with attenuated $\mathrm{p} 21$. MDCK were cells treated with roscovitine (Ros, $\mu \mathrm{g} / \mathrm{ml}$ ) at concentrations indicated and caspase- 3 activity was measured as described in the Methods section. An immunoblot of similar passage cells at similar roscovitine concentrations is shown at the bottom for comparison. ${ }^{*} \mathrm{p}<0.05$ as compared to complete media without roscovitine $(\mathrm{CM})$. Shown are representative experiments of at least three repetitions.

ible cell cycle arrest, has the incontrovertible potential to beneficially modulate the aberrant cell proliferation seen in this disease. In addition, senescence is triggered by $\mathrm{p} 21$ [18-20], which we show is increased only at low-dose roscovitine (fig. 1). Thus, we examined roscovitine-stimulated cells for SA- $\beta$-galatosidase activity as a biomarker for senescence [9]. We utilized MDCK cells as well as the human ADPKD cell line (WT 9-7). While there was minimal blue staining in the control cells, staining increased progressively in cells incubated with roscovitine (fig. 3), indicating that these low doses of roscovitine caused these cells to become senescent [9]. At high roscovitine concentrations $(>10 \mu \mathrm{g} / \mathrm{ml}$ in MDCK and $>3 \mu \mathrm{g} / \mathrm{ml}$ in WT 9-7 cells), cell staining could not be accomplished since the cells became detached from the plate, consistent with the apoptotic phenotype described earlier (fig. 1). Thus, low-dose treatment of RTEs with roscovitine causes them to enter the state of replicative senescence, whereas, as shown previously, high dose results in apoptosis.

In order to ascertain the mechanism by which these disparate effects occur, we next examined proteins in ad- 


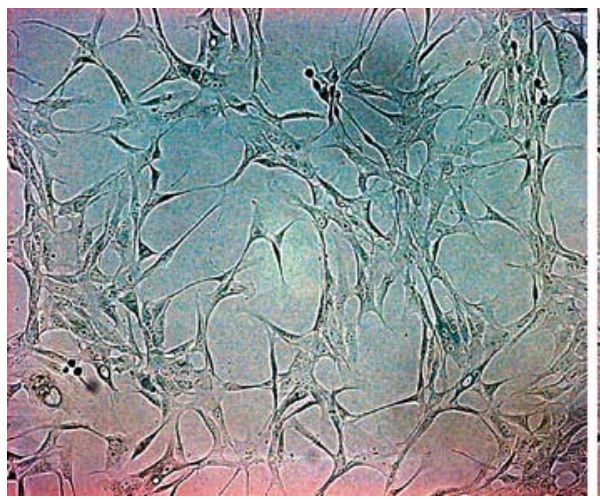

Control

a

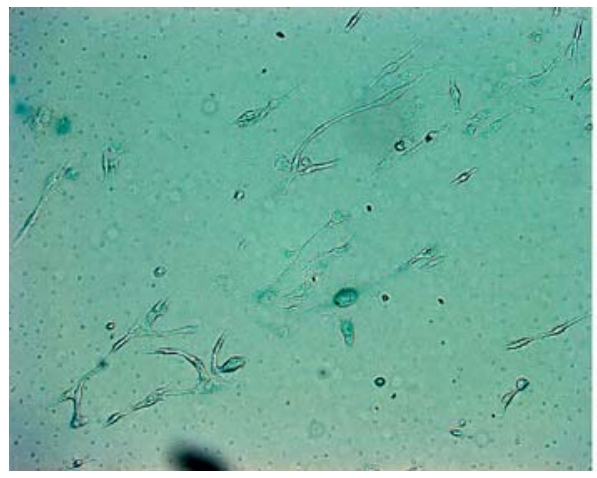

Control

b

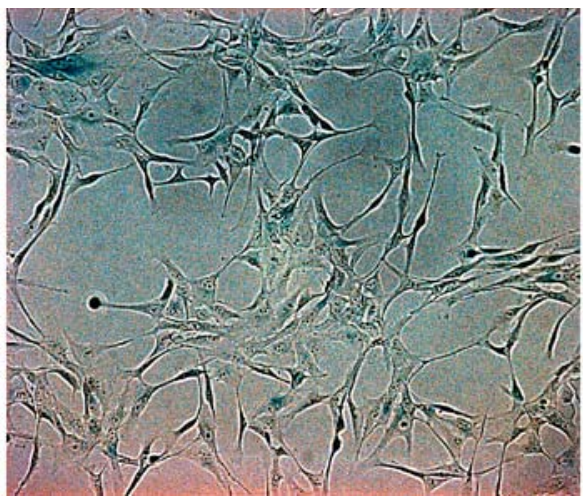

$5 \mu \mathrm{g} / \mathrm{ml}$ Ros

30

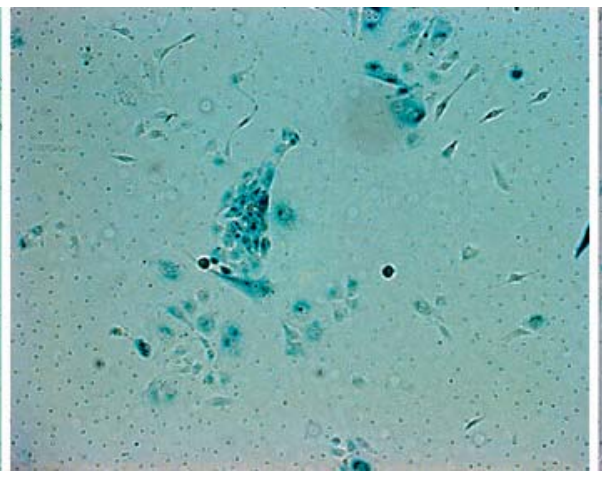

$1 \mu \mathrm{g} / \mathrm{ml}$ Ros

25

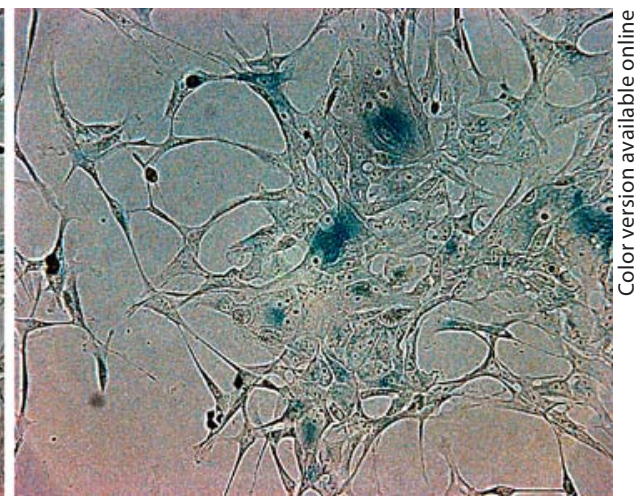

$10 \mu \mathrm{g} / \mathrm{ml}$ Ros

38

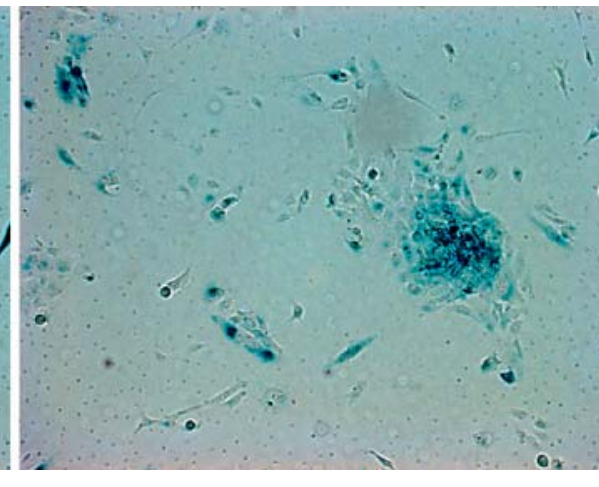

$3 \mu \mathrm{g} / \mathrm{ml}$ Ros

34
Fig. 3. Lower concentrations of roscovitine (Ros) cause senescence. MDCK cells (a) and WT 9-7 cells (b) were grown to confluence in $10 \%$ serum-containing media and roscovitine was added at concentrations indicated for $24 \mathrm{~h}$. The cells were fixed and stained for senescence-associated $\beta$-galactosidase as described in the Methods section. The percentage of stained cells is indicated under each panel and is an average of 2 random fields. Shown is a representative experiment of three repetitions. dition to p21 which are involved in both DNA damage/ repair and apoptosis signaling cascades. Upon DNA damage, ATM is activated as a sensor of damage leading to its phosphorylation, which subsequently leads to phosphorylation and stabilization of p53 and phosphorylation of Akt, presumably in an attempt to repair this damage $[21,22]$. Active Akt and p21 are responsible for the antiapoptotic state which is necessary for DNA repair. MDCK cells exposed to low-dose roscovitine for $24 \mathrm{~h}$, which we have shown become senescent, show evidence of DNA damage as indicated by phosphorylation of ATM, p53 and Akt, while cells exposed to high-dose roscovitine, which become apoptotic, did not result in activation of the DNA damage/repair pathway (fig. 4). Nonphosphorylated p53, the inactive form, did not show any changes with high-dose roscovitine.
Examination of apoptotic proteins was next undertaken. After $24 \mathrm{~h}$ of high-dose roscovitine, the antiapoptotic proteins XIAP, Bcl-2, and phospho-Bad were decreased, yet the proapoptotic protein Bax was augmented in MDCK cells but not significantly altered in WT 9-7 cells (fig. 5), consistent with a prior report of the role of Bax in roscovitine-mediated apoptosis in cancer cell lines [23]. Again, the sharp demarcation between low- and highdose roscovitine was evident in the expression of these signaling proteins.

\section{Discussion}

The CDK inhibitors, both endogenous (for example, p21) and synthetic (for example, roscovitine), have shown promise in the treatment of cancer [reviewed in 5], and 
Fig. 4. Lower doses of roscovitine (Ros) lead to activation of DNA damage, repair, and survival pathways. MDCK and WT 97 cells were grown to confluence in $10 \%$ serum-containing media (complete media without roscovitine) and roscovitine was added at concentrations indicated for $24 \mathrm{~h}$, and subsequently the cells were lysed and immunoblotted with the antibodies indicated. Doxorubicin (Doxo) at 2 and $4 \mu \mathrm{M}$ are positive controls for DNA damage. Shown is a representative experiment of at least three repetitions.

Fig. 5. Lower doses of roscovitine (Ros) lead to induction of antiapoptotic and higher doses of a proapoptotic protein. MDCK and WT 9-7 cells were grown to confluence in $10 \%$ serum-containing media (complete media without roscovitine) and roscovitine was added at concentrations indicated for $24 \mathrm{~h}$, and subsequently the cells were lysed and immunoblotted with the antibodies indicated. Shown is a representative experiment of at least three repetitions.
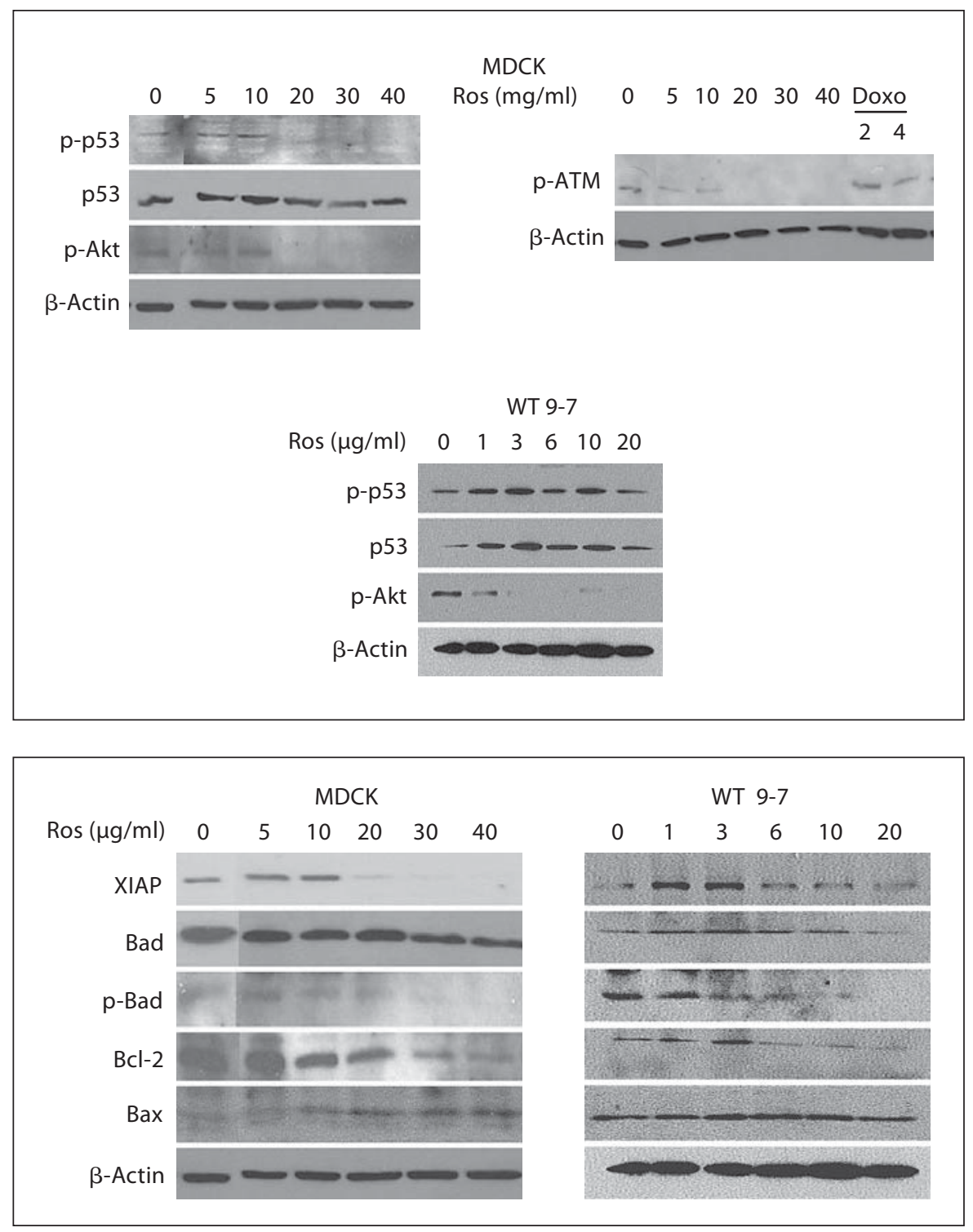

more recently, of ADPKD [8]. While this is not surprising given that both diseases are characterized by excessive cell proliferation, it is unexpected in that these diseases are at opposite ends of the apoptosis spectrum: apoptosis being desirable in cancer chemotherapy, yet detrimental in PKD. In this study, we sought to determine how roscovitine can have these disparate effects yet be effective in both diseases. Our results indicate that this drug has pleiotropic effects in RTE cells over a quite narrow range of concentrations, being senescence-inducing and antiapoptotic at low concentrations, and apoptosis-inducing at higher concentrations.

Effects of Roscovitine on RTE Cell Apoptosis and Senescence
Since p21 is in general an antiapoptotic protein $[11,12]$, and because we have previously shown that p21 is decreased in PKD and increased in MDCK cells exposed to roscovitine [7], it was logical to expect that p21 may be dictating, or at least functioning as a read-out of, the disparate roscovitine effects. Our finding that p21 correlates with antiapoptosis across all concentrations suggests that upregulation of $\mathrm{p} 21$ is a mechanism by which roscovitine exerts its varied effects. Further examination of other proand antiapoptotic signaling molecules has shown that the profile of expression of these proteins parallel the apoptotic changes in the cells. The Bcl-2 family is comprised of proapoptotic members such as Bad and Bax as well as an- 
tiapoptotic proteins such as $\mathrm{Bcl}-2$; these proteins regulate the intrinsic apoptotic pathway. The oncogene $\mathrm{Bcl}-2$ exerts a survival function and thus blocks cell death in response to a variety of apoptotic stimuli, while the proapoptotic Bax [23] is maintained in an inactive conformation through direct interactions with the antiapoptotic Bcl-2 protein. We show that high-dose, but not low-dose, roscovitine decreased $\mathrm{Bcl}-2$ such that Bax can be released to initiate apoptosis $[24,25]$. Our data is consistent with that in another study which demonstrated that high levels of Bcl-2 prevent apoptosis as well as cyst formation in MDCK cells [4]. Furthermore, because the level of Bad, another proapoptotic member of the Bcl-2 family, was slightly decreased, we further tested the level of phosphorylated Bad (the active form) and found that it was more markedly decreased at high-dose roscovitine in both canine and human cell lines (fig. 5); this finding is consistent with prior studies showing that several kinases, including Akt, phosphorylate Bad and promote survival $[26,27]$. Thus, our studies indicated that low doses of roscovitine likely induce minor repairable damage to cells, which in turn cause activation of ATM, p53, and p21, and activate the Akt pathway, which prevents cells from entering the apoptosis pathway rather than the survival pathway. As a result, cells enter the permanent cell cycle arrest stage, or replicative senescence, which of course is an ideal result for a potential PKD therapeutic and a novel finding of our study.

The role of p21 as an indicator of apoptosis or senescence was confirmed in another human primary cell line, WT 9-7. However, these cells were more sensitive to the effect of roscovitine, causing p21 induction, apoptosis, and senescence at lower doses than the other cell lines examined. As in MDCK cells, antiapoptotic proteins such as Bcl-2 and Bax were decreased at apoptosis-inducing doses of roscovitine, yet the proapoptotic molecule Bax, although slightly increased, was not as pronounced. Although apoptosis occurs in WT 9-7 at a lower dose than in MDCK cells, the profile of proteins in the apoptosis pathway is similar, and the decreased level of p21 associated with apoptosis indicated that these proteins likely contribute to the observed apoptosis. This finding strongly suggests that only a low dose of roscotivine, sufficient for RTE cells to enter the senescence but not the apoptotic pathway, will be effective in human PKD treatment.

In the recent study reporting a salutary effect of roscovitine in murine $\mathrm{PKD}$, neither serum nor urine concentrations of drug were measured [8]. However, an approximation of the urine concentration to which RTEs are exposed can be made based on published pharmacokinetic data [28]. Using these data, which showed that $0.02 \%$ of the administered roscovitine dose was excreted into the urine for up to $24 \mathrm{~h}$, and using the described dose of 50 $\mathrm{mg} / \mathrm{kg}$ [8] in a mouse of 20-30 g urinating $0.5-1 \mathrm{ml} / 24 \mathrm{~h}$ (http://www.jhu.edu/animalcare/Mouse.HTM), the calculated concentration of roscovitine in the urine in those animals is at most $0.3-0.4 \mu \mathrm{g} / \mathrm{ml}$; for $150 \mathrm{mg} / \mathrm{ml}$, the calculated concentration is $0.9-1.2 \mu \mathrm{g} / \mathrm{ml}$. These concentrations are well within the low concentration of roscovitine in our study and thus could be expected to result in therapeutic senescence rather than apoptosis of RTE cells.

Our finding that an effective PKD therapeutic intervention results in the induction of senescence is consistent with the known role of $\mathrm{p} 21$ in this disease. It has been shown that $\mathrm{p} 21$ is induced by the product of the $P k d 1$ gene, polycystin-1 [6], and work from our laboratory has shown that p21 is attenuated in human disease [7]. That low-dose roscovitine induces senescent markers in association with p21 augmentation is consistent with the known role of p21 in causing replicative senescence and its absence in avoiding this fate [18-20,29], and suggests that these events are mechanistically related. In addition, our finding that senescence occurs with use of an effective drug suggests that senescence may be a mechanism by which normal tubular cells (i.e. those with intact p21) are prevented from assuming a cystic phenotype. Furthermore, induction of the senescent state by low-dose roscovitine, as we describe here, explains the observed (and tantalizing) long-lasting nature of roscovitine in arresting murine PKD progression [8].

Our data provide an explanation of how a CDK inhibitor can be effective in both PKD and cancer, diseases with opposite degrees of apoptosis, with the level of p21 being an indicator as to whether cells enter either the replicative senescence or apoptosis pathway. In addition, our finding of senescence induction may explain how it is that early treatment with roscovitine leads to lasting effects. In light of our findings, caution should be used in future studies with roscovitine such that the range of concentration for a particular disease is appropriate in light of this drug's function in apoptosis and senescence. In addition, further work should be directed at the promotion of senescence, by therapeutic or other means, as a potential therapeutic intervention in ADPKD.

\section{Acknowledgements}

This work was supported by grant 1R21CA 91259-01A1 and the Early Detection Research Network from the NCI, the Research Service of the US Department of Veterans' Affairs, and grants from the Morris Animal Foundation and Dialysis Clinics, Inc. 


\section{References}

1 Grantham JJ: Polycystic kidney disease: neoplasia in disguise. Am J Kidney Dis 1990;15: 110-116.

$\checkmark 2$ Woo D: Apoptosis and loss of renal tissue in polycystic kidney diseases. N Engl J Med 1995;333:18-25.

3 Evan GI, Vousden KH: Proliferation, cell cycle and apoptosis in cancer. Nature 2001;411: 342-348.

$\checkmark 4$ Lin HH, Yang TP, Jiang ST, Yang HY, Tang MJ: Bcl-2 overexpression prevents apoptosisinduced Madin-Darby canine kidney simple epithelial cyst formation. Kidney Int 1999; 55:168-178.

$\checkmark 5$ Weiss RH: p21Waf1/Cipl as a therapeutic target in breast and other cancers. Cancer Cell 2003;4:425-429.

-6 Bhunia AK, Piontek K, Boletta A, Liu L, Qian F, Xu PN, Germino FJ, Germino GG: PKD1 induces p21(waf1) and regulation of the cell cycle via direct activation of the JAK-STAT signaling pathway in a process requiring PKD2. Cell 2002;109:157-168.

7 Park JY, Schutzer WE, Lindsley JN, Bagby SP, Oyama TT, Anderson S, Weiss RH: p21 is decreased in polycystic kidney disease and leads to increased epithelial cell cycle progression: roscovitine augments p21 levels. BMC Nephrol 2007;8:12.

$\checkmark 8$ Bukanov NO, Smith LA, Klinger KW, Ledbetter SR, Ibraghimov-Beskrovnaya O: Long-lasting arrest of murine polycystic kidney disease with CDK inhibitor roscovitine. Nature 2006;444:949-952.

-9 Dimri GP, Lee X, Basile G, Acosta M, Scott G, Roskelley C, Medrano EE, Linskens M, Rubelj I, Pereira-Smith O: A biomarker that identifies senescent human cells in culture and in aging skin in vivo. Proc Natl Acad Sci USA 1995;92:9363-9367.

10 Edelstein CL: What is the role of tubular epithelial cell apoptosis in polycystic kidney disease. Cell Cycle 2005;4:1550-1554.

- 11 Asada M, Yamada T, Ichijo H, Delia D, Miyazono K, Fukumuro K, Mizutani S: Apoptosis inhibitory activity of cytoplasmic p21(Cip1/WAF1) in monocytic differentiation. EMBO J 1999;18:1223-1234.
12 Fan Y, Borowsky AD, Weiss RH: An antisense oligodeoxynucleotide to p21(Waf1/ Cip1) causes apoptosis in human breast cancer cells. Mol Cancer Ther 2003;2:773-782.

13 Boletta A, Qian F, Onuchic LF, Bhunia AK, Phakdeekitcharoen B, Hanaoka K, Guggino W, Monaco L, Germino GG: Polycystin-1, the gene product of $\mathrm{PKD} 1$, induces resistance to apoptosis and spontaneous tubulogenesis in MDCK cells. Mol Cell 2000;6:1267-1273.

14 Tao Y, Kim J, Faubel S, Wu JC, Falk SA, Schrier RW, Edelstein CL: Caspase inhibition reduces tubular apoptosis and proliferation and slows disease progression in polycystic kidney disease. Proc Natl Acad Sci USA 2005;102:6954-6959.

15 Tao Y, Zafar I, Kim J, Schrier RW, Edelstein CL: Caspase-3 gene deletion prolongs survival in polycystic kidney disease. J Am Soc Nephrol 2008;19:749-755.

16 Shillingford JM, Murcia NS, Larson CH, Low SH, Hedgepeth R, Brown N, Flask CA, Novick AC, Goldfarb DA, Kramer-Zucker A, Walz G, Piontek KB, Germino GG, Weimbs T: The mTOR pathway is regulated by polycystin-1, and its inhibition reverses renal cystogenesis in polycystic kidney disease. Proc Natl Acad Sci USA 2006;103:54665471.

17 Tao Y, Kim J, Schrier RW, Edelstein CL: Rapamycin markedly slows disease progression in a rat model of polycystic kidney disease. J Am Soc Nephrol 2005;16:46-51.

-18 Han Z, Wei W, Dunaway S, Darnowski JW, Calabresi P, Sedivy J, Hendrickson EA, Balan KV, Pantazis P, Wyche JH: Role of p21 in apoptosis and senescence of human colon cancer cells treated with camptothecin. J Biol Chem 2002;277:17154-17160.

$>19$ Herbig U, Jobling WA, Chen BP, Chen DJ Sedivy JM: Telomere shortening triggers senescence of human cells through a pathway involving ATM, p53, and p21(CIP1), but not p16(INK4a). Mol Cell 2004;14:501-513.

20 Van Nguyen T, Puebla-Osorio N, Pang H, Dujka ME, Zhu C: DNA damage-induced cellular senescence is sufficient to suppress tumorigenesis: a mouse model. J Exp Med 2007;204:1453-1461.
21 Brognard J, Clark AS, Ni Y, Dennis PA: Akt/ protein kinase $\mathrm{B}$ is constitutively active in non-small cell lung cancer cells and promotes cellular survival and resistance to chemotherapy and radiation. Cancer Res 2001; 61:3986-3997.

22 Viniegra JG, Martinez N, Modirassari P, Losa JH, Parada CC, Lobo VJ, Luquero CI, Alvarez-Vallina L, Cajal S, Rojas JM, Sanchez-Prieto R: Full activation of PKB/Akt in response to insulin or ionizing radiation is mediated through ATM. J Biol Chem 2005; 280:4029-4036.

23 Tirado OM, Mateo-Lozano S, Notario V: Roscovitine is an effective inducer of apoptosis of Ewing's sarcoma family tumor cells in vitro and in vivo. Cancer Res 2005;65: 9320-9327.

$>24$ Finucane DM, Bossy-Wetzel E, Waterhouse NJ, Cotter TG, Green DR: Bax-induced caspase activation and apoptosis via cytochrome $c$ release from mitochondria is inhibitable by Bcl-xL. J Biol Chem 1999;274: 2225-2233.

25 Zheng Y, Yamaguchi H, Tian C, Lee MW, Tang H, Wang HG, Chen Q: Arsenic trioxide (As(2)O(3)) induces apoptosis through activation of Bax in hematopoietic cells. Oncogene 2005;24:3339-3347.

26 Datta SR, Dudek H, Tao X, Masters S, Fu H, Gotoh Y, Greenberg ME: Akt phosphorylation of BAD couples survival signals to the cell-intrinsic death machinery. Cell 1997;91: 231-241.

27 Zha J, Harada H, Yang E, Jockel J, Korsmeyer SJ: Serine phosphorylation of death agonist $\mathrm{BAD}$ in response to survival factor results in binding to 14-3-3 not BCL-X(L). Cell 1996; 87:619-628.

28 Nutley BP, Raynaud FI, Wilson SC, Fischer PM, Hayes A, Goddard PM, McClue SJ, Jarman M, Lane DP, Workman P: Metabolism and pharmacokinetics of the cyclin-dependent kinase inhibitor R-roscovitine in the mouse. Mol Cancer Ther 2005; 4:125-139.

29 Brown JP, Wei W, Sedivy JM: Bypass of senescence after disruption of p21CIP1/WAF1 gene in normal diploid human fibroblasts. Science 1997;277:831-834. 